\title{
(6) OPEN ACCESS \\ The impact of chronic use of prostaglandin analogues on the biomechanical properties of the cornea in patients with primary open-angle glaucoma
}

\author{
Roman Meda, ${ }^{1,2,{ }^{*}}$ Qianqian Wang, ${ }^{1,{ }^{*}}$ David Paoloni, ${ }^{3}$ Paul Harasymowycz, ${ }^{1,2,3,{ }^{* *}}$ \\ Isabelle Brunette $1,3,{ }^{* *}$
}

${ }^{1}$ Department of

Ophthalmology, University of Montreal, Montreal, Quebec, Canada

${ }^{2}$ Montreal Glaucoma Institute, Montreal, Quebec, Canada ${ }^{3}$ Maisonneuve-Rosemont Hospital Research Center, Montreal, Quebec, Canada

\section{Correspondence to} Dr Paul Harasymowycz, Department of Ophthalmology, Maisonneuve-Rosemont Hospital, 5415 boulevard de L'Assomption, Montreal, Quebec, Canada H1T 2M4; pavloh@igmtl.com

\section{${ }^{*} \mathrm{RM}$ and $\mathrm{QW}$ were equally involved. \\ ${ }^{*} \mathrm{PH}$ and $\mathrm{IB}$ were equally involved.}

Meeting presentation: Preliminary results presented in part at the Association for Research in Vision and Ophthalmology (ARVO) on 7 May 2014.

Received 22 January 2016 Revised 1 April 2016 Accepted 13 April 2016 Published Online First 9 May 2016

\section{CrossMark}

To cite: Meda R, Wang $Q$, Paoloni $\mathrm{D}$, et al. $\mathrm{Br}$ J

Ophthalmol 2017;101:120125.

\section{ABSTRACT}

Aims To determine the influence of prostaglandin analogues (PGAs) on corneal biomechanical properties in patients undergoing chronic treatment for primary openangle glaucoma (POAG).

Methods Prospective, interventional case-control study. 70 eyes from 35 patients with POAG on chronic PGA therapy were recruited. One eye per patient underwent PGA cessation for 6 weeks while the contralateral eye continued to receive the treatment. Corneal hysteresis $(\mathrm{CH})$, corneal resistance factor (CRF), corneal-compensated intraocular pressure (IOP) (IOPcc), central corneal thickness (CCT) and Goldmann tonometry (Haag-Streit AG, Koeniz, Switzerland) IOP (IOP GAT $)$ were measured at baseline (visit 1), 6 weeks after PGA cessation (visit 2) and 6 weeks after PGAs reinitiation (visit 3) and were analysed using a linear mixed-effect model. The discrepancy between IOPcc and IOP $\mathrm{PAT}_{\mathrm{GT}}$ was defined as IOP bias (IOPCC-IOP $\left.{ }_{\mathrm{GAT}}\right)$.

Results Baseline characteristics were comparable between the two groups. In the study eyes, significant increases $(p<0.0001)$ were detected at visit 2 in $\mathrm{CH}$ $(9.0 \pm 1.8$ vs $10.3 \pm 1.7 \mathrm{~mm} \mathrm{Hg}), \mathrm{CRF}(10.5 \pm 2.1$ vs 11.7 $\pm 2.1 \mathrm{~mm} \mathrm{Hg})$, CCT $(541.8 \pm 43.2$ vs $551.9 \pm 41.9 \mu \mathrm{m})$ and IOP GAT $_{\text {T }}(15.4 \pm 3.0$ vs $18.4 \pm 3.8 \mathrm{~mm} \mathrm{Hg})$. IOP bias in this group was significantly lowered at visit 2

$(p<0.0001)$. These effects were reversed at visit 3 . The control eyes did not demonstrate any significant changes over the study period.

Conclusion Topical PGAs induce reversible reduction in $\mathrm{CH}, \mathrm{CRF}$ and $\mathrm{CCT}$ in patients with POAG. These changes contribute to underestimation of the IOP measured by Goldmann applanation tonometry and warrant caution when assessing response to treatment.

Trial registration number NCT02388360, Results.

\section{INTRODUCTION}

Affecting approximately 67 million people worldwide, glaucoma is the second-leading cause globally for avoidable blindness. ${ }^{1}$ Intraocular pressure (IOP) remains the most important modifiable risk factor and is the sole target for the currently proven glaucoma therapies. The accuracy of its measurement therefore carries significant clinical impact.

Goldmann applanation tonometry is the gold standard technique for IOP measurement. It measures the force necessary to flatten a $3.06 \mathrm{~mm}$ diameter corneal surface area. The relationship between IOP readings and central corneal thickness (CCT) has long been recognised and several conversion scales were proposed to adjust IOP readings according to CCT values, though none provided reliable estimation. $^{2}$ Thinner CCT is associated with primary open-angle glaucoma (POAG) development and progression, ${ }^{3}$ leading to increasing interests in the relationship between glaucoma and corneal biomechanics. ${ }^{4}$

The Ocular Response Analyzer (ORA; Reichert, New York, USA), a non-touch tonometer, uses a rapid air jet to temporarily deform the corneal surface. It provides IOP readings adjusted for corneal biomechanics, as well as quantifiable viscoelastic parameters, including corneal hysteresis $(\mathrm{CH})$ and corneal resistance factor $(\mathrm{CRF}){ }^{5}$ For glaucoma management, $\mathrm{CH}$ is of special interest. A low $\mathrm{CH}$ has been associated with advanced glaucoma damage ${ }^{6}$ and with glaucoma progression. ${ }^{4}$ Moreover, several studies demonstrated recovery of $\mathrm{CH}$ following surgical ${ }^{7}$ or medical ${ }^{8-10}$ glaucoma treatment.

The objective of our study was to determine the effect of chronic use of topical prostaglandin analogues (PGAs) on corneal biomechanical properties in eyes with POAG.

\section{METHODS}

This research protocol adhered to the Declaration of Helsinki and was approved by the MaisonneuveRosemont Hospital Institutional Review Board (Montreal, Quebec, Canada; ClinicalTrials.gov no. NCT02833860). Informed consent was obtained from all participants.

\section{Patients}

Consecutive patients with bilateral POAG were recruited from the Montreal Glaucoma Institute (Montreal, Quebec, Canada). The diagnosis of POAG was made based on an open angle on gonioscopy examination, absence of signs suggesting secondary glaucoma and characteristic glaucomatous disc changes with corresponding visual field (VF) defects. All patients had been on topical PGA monotherapy with well-controlled IOP in both eyes for a minimum of 1 year. Exclusion criteria included factors affecting the corneal biomechanical properties: contact lens wear, history of corneal disease, trauma or surgery, refractive spherical equivalence outside the range of -6.00 to $+4.50 \mathrm{D}$ and systemic use of prostaglandin medications, non-steroidal anti-inflammatory drugs, hormonal replacement therapy, $\beta$-blockers, as well as carbonic anhydrase inhibitors. Patients with over target IOPs despite use of topical PGAs and those with advanced glaucoma were excluded for ethical reasons. Advanced glaucoma was defined as 
cup-to-disc (C:D) ratio $>0.9$ and/or VF defect within $10^{\circ}$ of fixation (eg, mean deviation (MD) worse than $-12 \mathrm{~dB}$ on the Humphrey VF (HFA, Carl Zeiss Meditec, Dublin, California, USA)). ${ }^{11}$

\section{Study procedures}

The study comprised three visits over 12 weeks. Corneal biomechanical properties, IOP and CCT were measured at all visits. At visit 1 , patients were evaluated for glaucomatous damage and were instructed to discontinue the PGA in their better eye (study eye) for 6 weeks, while continuing the medication in the contralateral one (control). The better eye was selected based on a combined evaluation encompassing the following parameters, listed in the order with decreasing clinical weight in the selection process: $\mathrm{MD}$ on the Humphrey $\mathrm{VF}$ analyser using the white-on-white 24-2 Swedish Interactive Threshold Algorithm standard strategy 24-2 (HFA, Carl Zeiss Meditec, Dublin, California, USA), the mean retinal nerve fibre layer (RNFL) thickness on optical coherence tomography (OCT) (Cirrus HD-OCT, Carl Zeiss Meditec, Dublin, California, USA), C:D ratio on Heidelberg Retinal Tomograph (HRT II, Heidelberg Engineering GmbH, Heidelberg, Germany) and the recorded maximal IOP value. Based on these clinical data, each eye was also classified as having mild or moderate glaucoma. Mild glaucoma was defined as C:D ratio $<0.65$ and/or mild VF defect not within $10^{\circ}$ of fixation (MD better than $-6 \mathrm{~dB}$ on Humphrey VF), whereas moderate glaucoma was defined as C: D ratio $0.7-0.85$ and/or $\mathrm{VF}$ defect not within $10^{\circ}$ of fixation (MD from -6 to $-12 \mathrm{~dB}$ on Humphrey VF). ${ }^{11}$

Visit 2 took place 6 weeks after the PGA cessation. PGAs were then restarted in the study eyes and all eyes were reassessed after another 6 weeks, at visit 3 . All serial measurements were performed by the same trained, unmasked observer (RM), with the same rigorous approach, using the same calibrated equipment and at the same time of day for each patient.

\section{Corneal biomechanical parameters measurement}

The ORA was used to assess the corneal biomechanical properties. Four sequential ORA assessments were done for each eye and the average values for $\mathrm{CH}$ and $\mathrm{CRF}$ were recorded. Details of this instrument"s function have been previously described. ${ }^{45}$ Briefly, the device emits a rapid air pulse that pushes the cornea inward, past an applanated state and into a slight concavity. The air pump shuts off milliseconds after the first applanation, allowing the cornea to return to its natural shape as the pressure declines, passing once again through an applanation state. This bidirectional process is closely monitored by an electro-optical system that captures both applanation times. $\mathrm{CH}$ is defined as the difference between the inward and outward applanation pressures $(\mathrm{CH}=\mathrm{P} 1-\mathrm{P} 2)$ and represents the cornea"s viscous damping capacity. CRF is an indicator of the overall resistance of the cornea, that is, of the cumulative effect of viscous and elastic resistance encountered by the air jet while it deforms the corneal surface $(\mathrm{CRF}=\mathrm{k} 1 \times(\mathrm{P} 1-0.7 \times \mathrm{P} 2)+\mathrm{k} 2$, where the constants $\mathrm{k} 1$ and $\mathrm{k} 2$ have been empirically determined). ${ }^{5}$

\section{IOP measurement}

Goldmann applanation tonometry (Haag-Streit AG, Koeniz, Switzerland) was used to record conventional IOP ( IOP $_{\mathrm{GAT}}$ ) and the ORA was used to generate the corneal-compensated IOP (IOPcc). ${ }^{5}$ Similar to $\mathrm{CH}$ and CRF, the average value of four sequential measurements was recorded.

The difference between IOPcc and $\mathrm{IOP}_{\mathrm{GAT}}$ was calculated for each eye and was termed IOP bias (IOP bias $=\mathrm{IOPcc}_{-} \mathrm{IOP}_{\mathrm{GAT}}$ ).
A positive bias value indicated an underestimation by Goldmann applanation tonometry in comparison with the ORA, whereas a negative IOP bias value suggested an overestimation by the former.

\section{CCT measurement}

The average of three CCT measurements, determined by ultrasound pachymetry (DGH Technology, Exton, Pennsylvania, USA), was recorded.

\section{Statistical analysis}

Statistical analyses were performed using R (V.3.1.0). Continuous data were presented as mean \pm SE. Baseline quantitative data were compared between matched study and control eyes using paired $t$ test. The null hypotheses of the impact of discontinuing PGAs on corneal biomechanical properties, IOP and IOP bias were examined using a linear mixed-effect model. Random effects were defined on two levels: (1) the patient and (2) the eye for each patient. Age was included in the model as a covariate. Contrasts between the eyes and times were estimated using adjusted $\mathrm{p}$ values to control for family-wise error rate. The associations between glaucomatous damage and corneal biomechanical properties were also examined using a linear mixed-effect model adjusted for the patient random effect.

\section{RESULTS}

Thirty-five patients (16 men and 19 women; 70 eyes) with POAG were recruited. The mean age was $69.0 \pm 1.6$ years $(50-$ 85 years) and the mean spherical equivalent was $-0.10 \pm 0.46 \mathrm{D}$ $(-6.00$ to $4.25 \mathrm{D})$. At the time of enrolment, patients had been on PGAs for $3.99 \pm 0.28$ years (1-7 years). The topical PGAs used included bimatoprost (Lumigan RC, Allergan Markham, Ontario, Canada) (8 patients), latanoprost (Xalatan, Pfizer Canada Kirkland, Quebec, Canada) (15 patients)/(APO Latanoprost, Apotex, Macquarie Park, New South Wales, Australia) (1 patient) and travoprost (Travatan Z, Alcon Canada Mississauga, Ontario, Canada) (11 patients).

All tested eyes underwent significant increases in $\mathrm{CH}$ (figure $1 \mathrm{~A}$ ), $\mathrm{CRF}$ (figure 1B), CCT (figure 1C) and $\mathrm{IOP}_{\mathrm{GAT}}$ (figure 1D) 6 weeks after PGA cessation (visit 2 vs visit $1 ; p<0.00001$ ). In all cases, subsequently restarting PGAs induced changes of similar magnitude in the opposite direction (visit 3 vs visit 2 ; $\mathrm{p}<0.00001$ ). While there were no significant differences between the two groups at visits 1 and 3 ( $p>0.05)$, all four parameters were significantly higher in the study eyes compared with controls at visit $2(p<0.001)$. No significant changes were detected among control eyes during the study period for these four parameters.

IOP bias baseline values were similar in both groups (table 1). A decrease in IOP bias values was detected in study eyes at visit $2(\mathrm{p}<0.0001)$, subsequently followed by a marginally significant increase $(p=0.0553)$ after reinitiation of PGAs at visit 3 (figure 1E). Discontinuation of PGAs reduced underestimation of IOP by a mean of $3.2 \pm 0.6 \mathrm{~mm} \mathrm{Hg}$, the mean difference between IOPcc and $\mathrm{IOP}_{\mathrm{GAT}}$ decreasing to $-1.2 \mathrm{~mm} \mathrm{Hg}$ at visit 2 . No significant change in IOP bias was detected among control eyes during the study period.

Analysis of the interaction between IOP bias, $\mathrm{CH}$ and CCT revealed the following: a moderate negative correlation was observed between IOP bias and $\mathrm{CH}(\mathrm{r}=-0.4979, \mathrm{p}<0.0001$; figure 2A), whether the eyes were on PGAs $(r=-0.4736$, $\mathrm{p}=0.0041)$ or not $(\mathrm{r}=-0.5058, \mathrm{p}<0.0001)$. A moderate positive correlation was also observed between $\mathrm{CH}$ and CCT $(\mathrm{r}=0.4432, \mathrm{p}<0.0001$; figure $2 \mathrm{~B})$. 
A

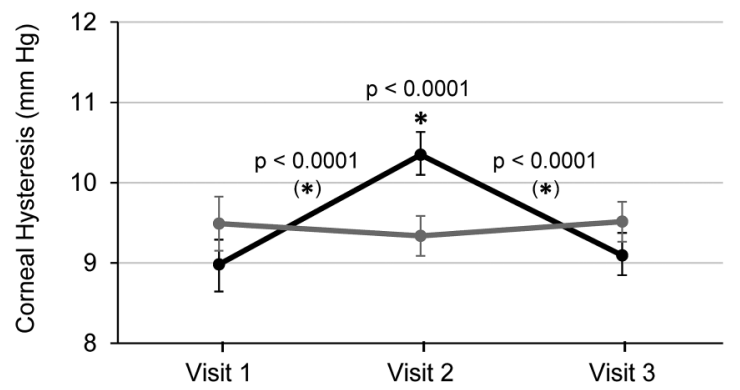

C

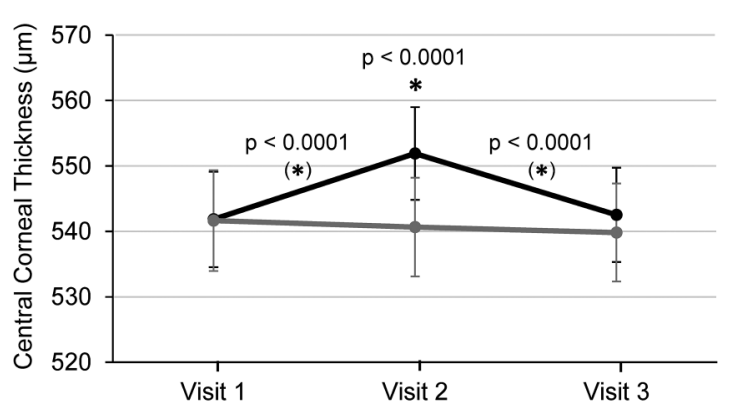

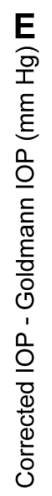

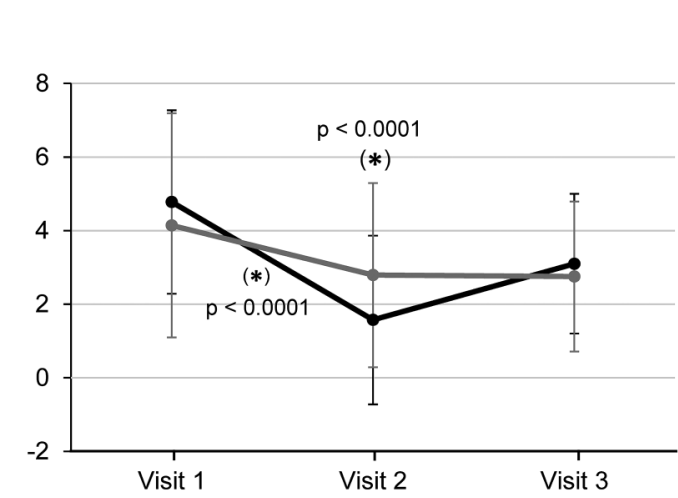

B

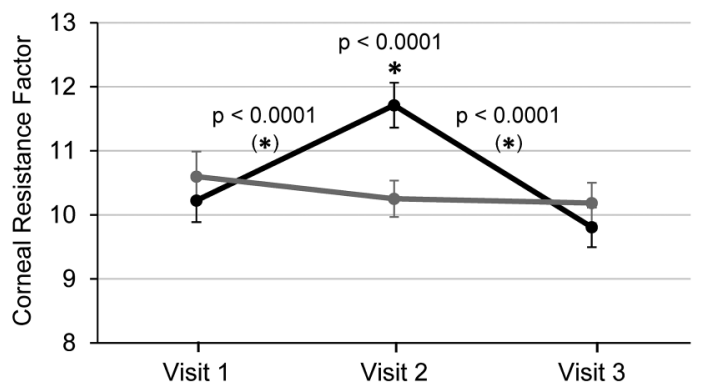

D

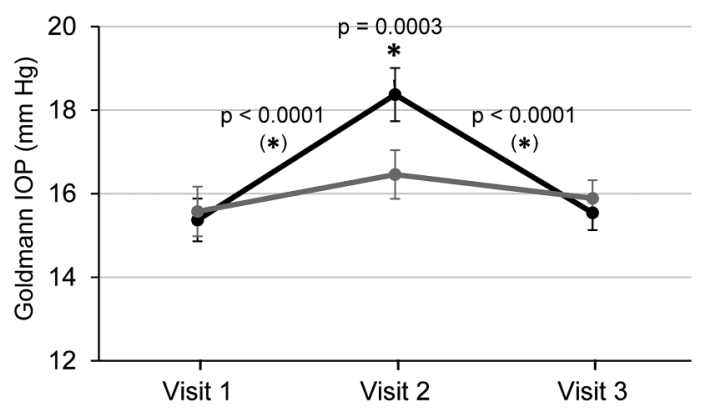

- Control eye

- Study eye

* Difference between Control and Study eyes reaches statistical significance

(*) Difference between Visits in Study eyes reaches statistical significance

Figure 1 Evolution of corneal biomechanics and Goldmann intraocular pressure (IOP) in control and study eyes is shown. (A) Corneal hysteresis; (B) corneal resistance factor; (C) central corneal thickness; (D) Goldmann IOP and (E) IOP bias are shown. IOP bias=corneal-compensated IOP (IOPcC) -Goldmann IOP (IOP $\mathrm{GAT})$. Means and SEs are represented.

We also examined our cohort of patients for associations between corneal biomechanical properties ( $\mathrm{CH}$ and $\mathrm{CRF}$ ) and indices of glaucoma severity (MD on baseline Humphrey VF and RNFL thickness on OCT). Five eyes from the study group and seven eyes from the control group were classified as having moderate glaucoma. All other eyes were classified as having mild glaucoma. Statistically significant positive correlations were found between $\mathrm{MD}$ and $\mathrm{CH}$ (figure $3 \mathrm{~A}$ ), $\mathrm{MD}$ and $\mathrm{CRF}$ (figure 3B), RNFL thickness and $\mathrm{CH}$ (figure 3C) and RNFL and CRF (figure $3 \mathrm{D}$ ) in the subgroup with moderate glaucoma. No similar tendencies were observed in eyes diagnosed with mild glaucoma.

\section{DISCUSSION}

We herein demonstrated that the cessation of chronic topical PGAs was associated with significant increases in $\mathrm{CH}$, CRF and CCT, in addition to the expected elevation of IOP and that reinitiation of the medication reversed these effects. Until now, initiation of PGA treatment in previously naïve eyes has been associated with $\mathrm{CH}$ increase in glaucomatous eyes, ${ }^{8} 9$ which is opposite our findings in patients under chronic treatment. The strengths of this study include its prospective design, with reinitiation of PGAs 6 weeks after the initial cessation, the absence of dropouts and the use of contralateral eyes as controls.

$\mathrm{CH}, \mathrm{CRF}$ and CCT are significantly positively correlated. ${ }^{5}$ $\mathrm{CH}$ has incited much interest in recent years for its implication in glaucoma, ${ }_{4} 6812$ although the exact relationship between $\mathrm{CH}$ and glaucoma is not entirely understood. The biomechanics of the peripapillary sclera and lamina cribosa were found to play a crucial role in glaucoma pathogenesis. The scleral canal, sole opening in a pressurised globe, is a major stress-bearing area. ${ }^{13}$ Experimental murine models have shown that strains with stiffer sclera and greater resistance to deformation are less susceptible to glaucomatous damage. ${ }^{14}$ The cornea being in continuity with the posterior scleral wall, it is speculated that $\mathrm{CH}$ serves as a surrogate measure of the ability of the posterior segment in withstanding stress. This hypothesis resonates with Bochmann et al's ${ }^{15}$ observation of lower $\mathrm{CH}$ in glaucomatous eyes with acquired optic pit. In a prospective study by Wells et $a l^{16}$ where transient IOP elevation was induced in normal patients and patients with glaucoma, a significant correlation between $\mathrm{CH}$ and optic nerve surface deformation was found only in glaucomatous eyes. Patients with glaucoma were found to have lower $\mathrm{CH}$ than normal subjects and those with ocular hypertension. ${ }^{12} \mathrm{~A}$ low $\mathrm{CH}$ is associated with IOP 
Table 1 Baseline quantitative parameters of the matched experimental versus control eyes

\begin{tabular}{|c|c|c|c|}
\hline Baseline parameter & $\begin{array}{l}\text { Experimental } \\
\text { eye }(n=35)\end{array}$ & $\begin{array}{l}\text { Control eye } \\
(n=35)\end{array}$ & p Value* \\
\hline IOPmax (mm Hg) & $22.23 \pm 0.95$ & $20.80 \pm 0.82$ & 0.0002 \\
\hline Refractive errors (D) & $-0.07 \pm 0.44$ & $-0.14 \pm 0.47$ & 0.6556 \\
\hline $\mathrm{CH}(\mathrm{mm} \mathrm{Hg})$ & $8.98 \pm 0.31$ & $9.49 \pm 0.34$ & 0.0133 \\
\hline CRF & $10.23 \pm 0.34$ & $10.60 \pm 0.39$ & 0.0674 \\
\hline $\mathrm{CCT}(\mu \mathrm{m})$ & $541.83 \pm 7.30$ & $541.66 \pm 7.70$ & 0.9210 \\
\hline IOPcc (mm Hg) & $20.15 \pm 0.77$ & $19.71 \pm 0.89$ & 0.3134 \\
\hline IOPGAT (mm Hg) & $15.37 \pm 0.51$ & $15.57 \pm 0.59$ & 0.9297 \\
\hline IOP bias $(\mathrm{mm} \mathrm{Hg})$ & $4.78 \pm 0.56$ & $4.14 \pm 0.69$ & 0.1343 \\
\hline C/D ratio & $0.58 \pm 0.03$ & $0.63 \pm 0.02$ & 0.0591 \\
\hline RNFL $(\mu \mathrm{m})$ & $81.33 \pm 2.63$ & $79.25 \pm 2.89$ & 0.1578 \\
\hline VF MD (dB) & $-2.13 \pm 1.01$ & $-2.95 \pm 0.88$ & 0.1603 \\
\hline \multicolumn{4}{|c|}{$\begin{array}{l}\text { All values are expressed as mean } \pm \text { SE. } \\
\text { *p Value is based on a paired t test. } \\
\text { C/D ratio, cup-to-disc ratio, as measured by Heidelberg Retinal Tomograph (HRT II, } \\
\text { Heidelberg Engineering GmbH, Heidelberg, Germany); CCT, central corneal thickness; } \\
\text { CH, Corneal Hysteresis; CRF, Corneal Resistance Factor; D, dioptres; IOPCC, } \\
\text { corneal-compensated intraocular pressure; IOPGAT, intraocular pressure measured by } \\
\text { Goldmann tonometry; RNFL, retinal neural fibre layer thickness, as measured by } \\
\text { Optical Coherence Tomography (Cirrus HD-OCT, Carl Zeiss Meditec, Dublin, California, } \\
\text { USA); VF MD, Humphrey 24-2 Swedish Interactive Threshold Algorithm (SITA) visual } \\
\text { field (HFA, Carl Zeiss Meditec, Dublin, California, USA) mean deviation. }\end{array}$} \\
\hline
\end{tabular}

underestimation $^{17}$ and is recognised as a risk factor for glaucoma progression. ${ }^{4} 6$

Topical PGAs are thought to lower IOP through increasing uveoscleral outflow, while having minimal impact on the traditional trabecular outflow. ${ }^{18}$ Homeostasis of ciliary muscle and sclera extracellular matrix (ECM), which contain collagen types I, III, IV, laminin and fibronectin, requires a fine balance between matrix metalloproteinases (MMP), that degrade specific proteins and the tissue inhibitors of matrix metalloproteinases (TIMP). ${ }^{18}$ Previous studies involving animal and human scleral tissues exposed to prostaglandins or PGAs demonstrated significant MMP upregulation and TIMP downregulation with the corresponding altered gene expression, ${ }^{19} 20$ suggesting that PGAs stimulate ECM degradation of ocular surface tissue by modulating the balance between these enzymes. Lopilly Park et $a l^{21}$ confirmed similar changes in vivo from human tear proteomics and conjunctival impression cytology. These authors also showed decreased collagen type I level and corneal thickness in PGAs-treated rabbit eyes, paralleling studies confirming corneal thinning in patients treated with PGAs. ${ }^{22}$ All this evidence corroborates our findings of significantly increased CCT upon cessation of chronic use of PGAs and its subsequent reduction following re-initiation of the medication. Along the same line, as $\mathrm{CH}$ and CRF reflect the corneal rigidity and ability of resisting strain, any structural weakening of the cornea is expected to result in reductions in these two parameters, as were suggested by our results.

Some authors found increased $\mathrm{CH}$ values following PGAs use. $^{8-10}$ These studies, however, were done in previously PGAs-naïve patients, contrary to our patients who were on PGA monotherapy for at least 1 year. The increase in $\mathrm{CH}$ invariably occurred within the first 6-12 months following therapy initiation, paralleling IOP lowering. ${ }^{8-10}$ As IOP reduction by other topical hypotensive medications ${ }^{23}$ and by various surgical interventions ${ }^{7}$ results in $\mathrm{CH}$ recovery, we hypothesise that the observed increase in $\mathrm{CH}$ in these studies may be largely due to IOP lowering, whereas the true effects of PGAs over corneal tissues remained camouflaged.
A

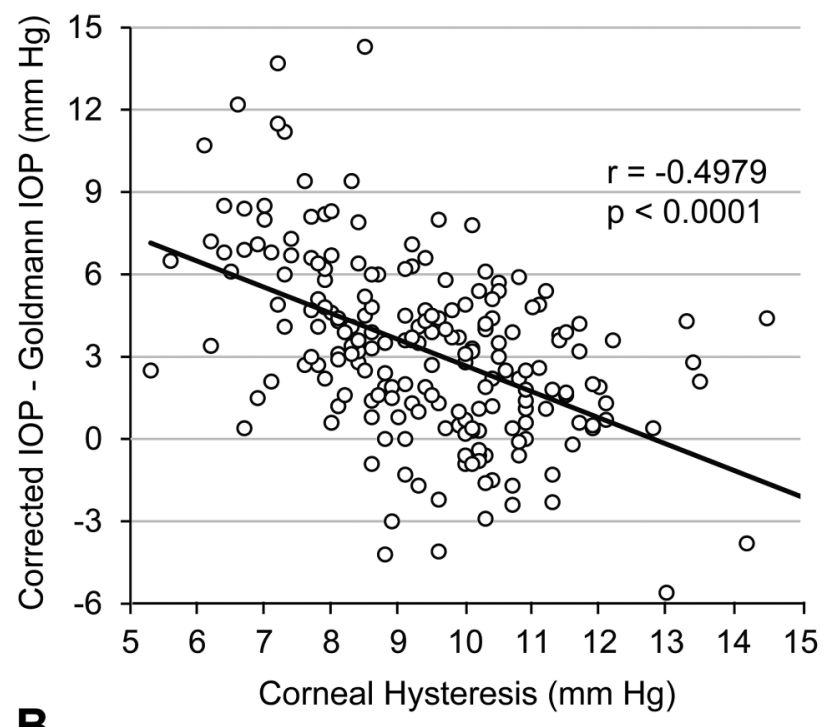

B

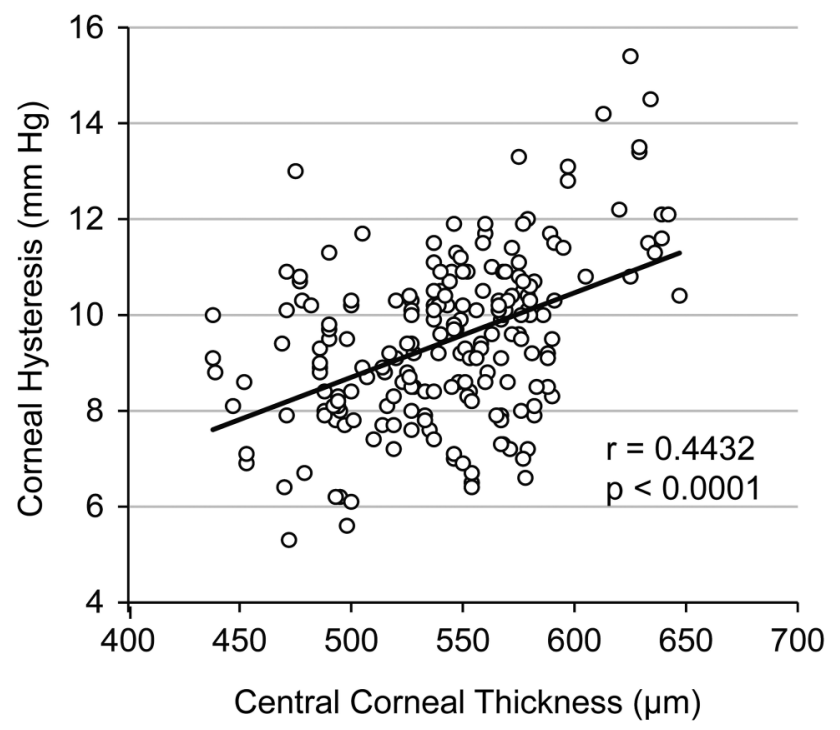

Figure 2 (A) Relationship between corneal hysteresis and intraocular pressure (IOP) bias. (B) Relationship between central corneal thickness and corneal hysteresis. IOPbias (IOP bias)=corneal-compensated IOP (IOPcc) - Goldmann IOP (IOP $\left.\mathrm{GAT}_{\mathrm{GT}}\right)$. Regression lines are shown, along with correlation coefficients $r$ and $p$ values.

In keeping with previous studies, our results confirmed the association between $\mathrm{CH}^{4}{ }^{6}$ and glaucoma damage, even though the study was not designed for this purpose. CRF also showed correlation to glaucoma damage. We observed significant positive correlations between $\mathrm{CH}$ and $\mathrm{CRF}$ and $\mathrm{MD}$ on baseline Humphrey VF and RNFL thickness on OCT, in patients with moderate glaucoma. Considering the association between $\mathrm{CH}$ and POAG and the dynamic nature of the former, it is possible that $\mathrm{CH}$ evolves as glaucoma progresses and that the association between the two becomes clinically more apparent in the later stages of the disease. In fact, a recent retrospective study has found a significantly greater rate of decline in $\mathrm{CH}$ over time in patients with POAG when compared with healthy controls, ${ }^{24}$ supporting our hypothesis.

In our study, the cessation of PGAs reduced IOP underestimation by Goldmann tonometry. This was not surprising given the established association between low $\mathrm{CH}$ and IOP 
A

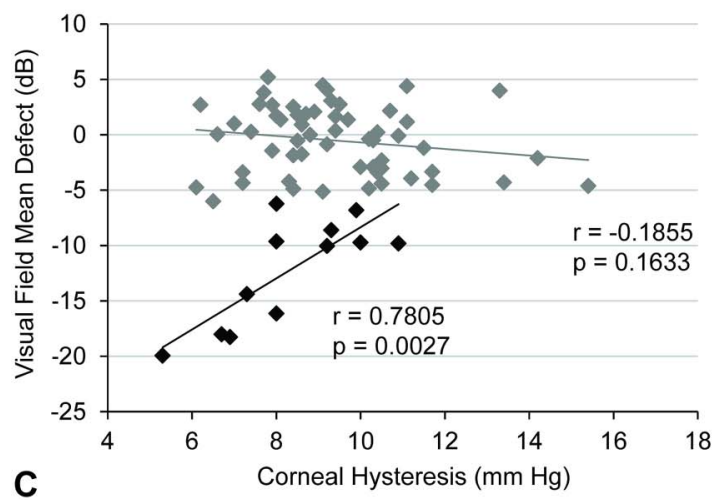

C

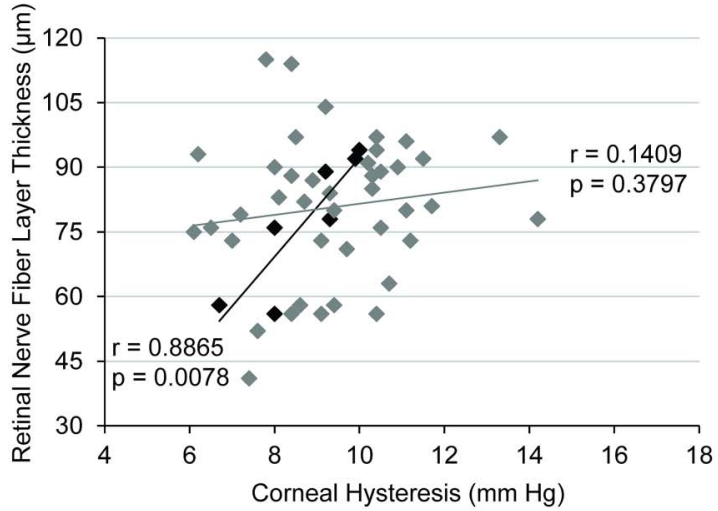

B
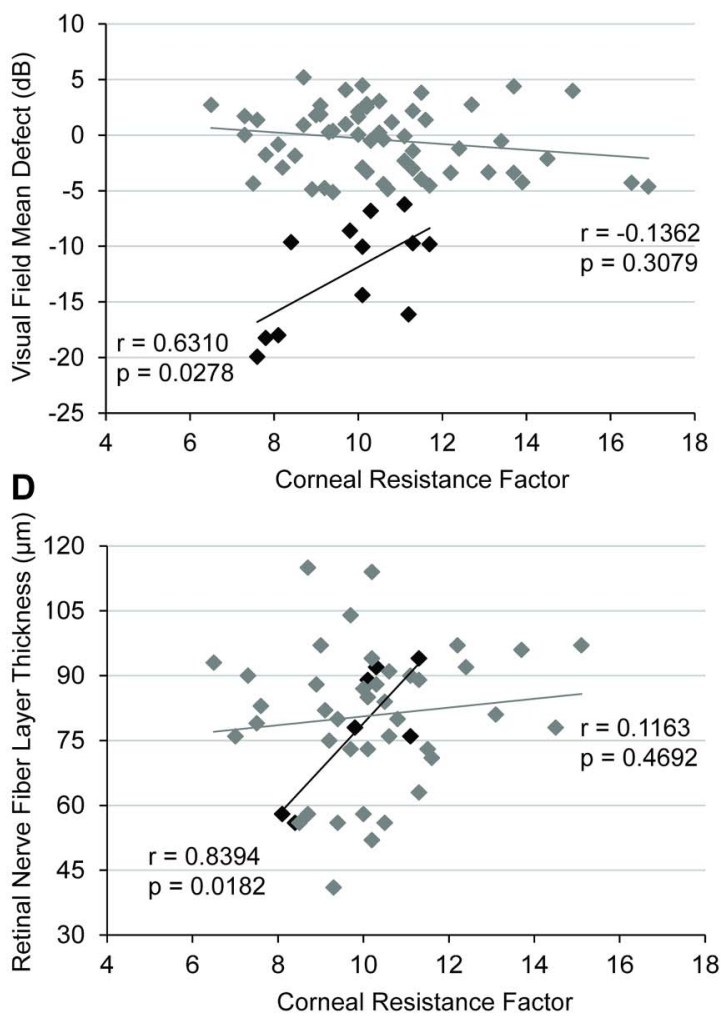

Figure 3 Correlations between Humphrey visual field damage at baseline and (A). Corneal Hysteresis and (B). Corneal Resistance Factor, in subgroups of patients with mild (grey squares) and moderate (black squares) primary open-angle glaucoma. Regression lines are shown, along with correlation coefficients $r$ and $p$ values.

underestimation and knowing that $\mathrm{CH}$ was lower in eyes treated with PGAs. ${ }^{17}$ This finding raises the concern over the accuracy of IOP measurement in patients under chronic PGAs therapy. In addition, recent studies suggested that lower baseline $\mathrm{CH}$ tends to result in greater IOP reduction following topical hypotensive therapy. ${ }^{8}$ This calls for additional caution when assessing the effectiveness of IOP lowering, especially in patients with more advanced glaucoma, which in itself tends to be associated with lower $\mathrm{CH}$.

In summary, we showed that patients on long term PGAs monotherapy had $\mathrm{CH}, \mathrm{CRF}$ and $\mathrm{CCT}$ values significantly inferior to those obtained when PGAs were discontinued. We also showed that Goldmann IOP was significantly underestimated while taking PGAs. We confirmed that IOP underestimation was more important in eyes with lower $\mathrm{CH}$ values and that $\mathrm{CH}$ and CCT were positively correlated in these eyes. Finally, among patients with glaucoma of moderate severity, lower $\mathrm{CH}$ and $\mathrm{CRF}$ values were associated with more severe damage, as measured by Humphrey VF MD and RNFL thickness on OCT. These results warrant caution when clinicians assess accuracy and adequacy of IOP control in patients under chronic PGAs therapy, especially in those with more advanced disease and lower $\mathrm{CH}$.

Acknowledgements The authors would like to thank Karolyn Forget, Ellen Freeman, Charles-Édouard Giguère and Leila Mejdoub for their knowledge and technical support.

Contributors This study was designed by PH and IB. Data were collected by RM and analysed by RM, QW and IB. The manuscript was drafted by RM, QW and DP and critically revised by IB and $\mathrm{PH}$.

Funding This work was supported by The FRQS Research in Vision Network, Montreal, QC, Canada. Funding organisation had no role in the design or conduct of this research.
Competing interests $\mathrm{PH}$ reports other grants from Allergan and Alcon.

Ethics approval Maisonneuve-Rosemont Hospital Institutional Review Board.

Provenance and peer review Not commissioned; externally peer reviewed.

Open Access This is an Open Access article distributed in accordance with the Creative Commons Attribution Non Commercial (CC BY-NC 4.0) license, which permits others to distribute, remix, adapt, build upon this work non-commercially, and license their derivative works on different terms, provided the original work is properly cited and the use is non-commercial. See: http://creativecommons.org/ licenses/by-nc/4.0/

\section{REFERENCES}

1 Quigley HA, Broman AT. The number of people with glaucoma worldwide in 2010 and 2020. Br J Ophthalmol 2006;90:262-7.

2 Gunvant $P, O^{\prime}$ Leary DJ, Baskaran $M$, et al. Evaluation of tonometric correction factors. J Glaucoma 2005;14:337-43.

3 Leske MC, Heijl A, Hyman L, et al. Predictors of long-term progression in the early manifest glaucoma trial. Ophthalmology 2007;114:1965-72.

4 Medeiros FA, Meira-Freitas D, Lisboa R, et al. Corneal hysteresis as a risk factor for glaucoma progression: a prospective longitudinal study. Ophthalmology 2013;120:1533-40.

5 Terai N, Raiskup F, Haustein M, et al. Identification of biomechanical properties of the cornea: the ocular response analyzer. Curr Eye Res 2012;37:553-62.

6 Congdon NG, Broman AT, Bandeen-Roche K, et al. Central corneal thickness and corneal hysteresis associated with glaucoma damage. Am J Ophthalmol 2006;141:868-75.

7 Pakravan M, Afroozifar M, Yazdani S. Corneal biomechanical changes following trabeculectomy, phaco-trabeculectomy, ahmed glaucoma valve implantation and phacoemulsification. J Ophthalmic Vis Res 2014;9:7-13.

8 Agarwal DR, Ehrlich JR, Shimmyo M, et al. The relationship between corneal hysteresis and the magnitude of intraocular pressure reduction with topical prostaglandin therapy. Br J Ophthalmol 2012;96:254-7.

9 Tsikripis P, Papaconstantinou D, Koutsandrea C, et al. The effect of prostaglandin analogs on the biomechanical properties and central thickness of the cornea of patients with open-angle glaucoma: a 3-year study on 108 eyes. Drug Des Devel Ther 2013;7:1149-56.

10 Bolivar G, Sanchez-Barahona C, Teus M, et al. Effect of topical prostaglandin analogues on corneal hysteresis. Acta Ophthalmol 2015;93:e495-8. 
11 Canadian Ophthalmological Society Glaucoma Clinical Practice Guideline Expert Committee; Canadian Ophthalmological Society. Canadian Ophthalmological Society evidence-based clinical practice guidelines for the management of glaucoma in the adult eye. Can J Ophthalmol 2009;44(Suppl 1):S7-93.

12 Detry-Morel M, Jamart J, Pourjavan S. Evaluation of corneal biomechanical properties with the Reichert Ocular Response Analyzer. Eur J Ophthalmol 2011;21:138-48.

13 HF DDUJE. Cornea and sclera. In: Levin LA, Nilsson SFE, Ver Hoeve J, et al., eds. Adler's physiology of the eye. 11 edn. Elsevier, 2011:71-130.

14 Cone FE, Gelman SE, Son JL, et al. Differential susceptibility to experimental glaucoma among 3 mouse strains using bead and viscoelastic injection. Exp Eye Res 2010;91:415-24.

15 Bochmann F, Ang GS, Azuara-Blanco A. Lower corneal hysteresis in glaucoma patients with acquired pit of the optic nerve (APON). Graefes Arch Clin Exp Ophthalmol 2008;246:735-8.

16 Wells AP, Garway-Heath DF, Poostchi A, et al. Corneal hysteresis but not corneal thickness correlates with optic nerve surface compliance in glaucoma patients. Invest Ophthalmol Vis Sci 2008;49:3262-8.

17 Touboul D, Roberts C, Kerautret J, et al. Correlations between corneal hysteresis, intraocular pressure, and corneal central pachymetry. J Cataract Refract Surg 2008;34:616-22.
18 Schachtschabel U, Lindsey JD, Weinreb RN. The mechanism of action of prostaglandins on uveoscleral outflow. Curr Opin Ophthalmol 2000;11:112-5.

19 Ito T, Ohguro H, Mamiya K, et al. Effects of antiglaucoma drops on MMP and TIMP balance in conjunctival and subconjunctival tissue. Invest Ophthalmol Vis Sci 2006;47:823-30.

20 Weinreb RN, Lindsey JD, Marchenko G, et al. Prostaglandin FP agonists alter metalloproteinase gene expression in sclera. Invest Ophthalmol Vis Sci 2004;45:4368-77.

21 Lopilly Park HY, Kim JH, Lee KM, et al. Effect of prostaglandin analogues on tear proteomics and expression of cytokines and matrix metalloproteinases in the conjunctiva and cornea. Exp Eye Res 2012;94:13-21.

22 Harasymowycz PJ, Papamatheakis DG, Ennis M, et al. Relationship between travoprost and central corneal thickness in ocular hypertension and open-angle glaucoma. Cornea 2007;26:34-41.

23 Sun L, Shen M, Wang J, et al. Recovery of corneal hysteresis after reduction of intraocular pressure in chronic primary angle-closure glaucoma. Am J Ophthalmol 2009;147:1061-6, 66 e1-2.

24 Hussnain SA, Alsberge JB, Ehrlich JR, et al. Change in corneal hysteresis over time in normal, glaucomatous and diabetic eyes. Acta Ophthalmol 2015;3: e627-30. 